University of Nebraska - Lincoln

DigitalCommons@University of Nebraska - Lincoln

USDA National Wildlife Research Center - Staff Publications
U.S. Department of Agriculture: Animal and Plant Health Inspection Service

January 2008

\title{
Food color, flavor, and conditioned avoidance among red-winged blackbirds
}

Scott J. Werner

USDA-APHIS-Wildlife Services, scott.j.werner@aphis.usda.gov

Bruce A. Kimball

USDA/APHIS/WS/National Wildlife Research Center, bruce.kimball@ars.usda.gov

Frederick D. Provenza

Utah State University, Logan, UT

Follow this and additional works at: https://digitalcommons.unl.edu/icwdm_usdanwrc

Part of the Environmental Sciences Commons

Werner, Scott J.; Kimball, Bruce A.; and Provenza, Frederick D., "Food color, flavor, and conditioned avoidance among red-winged blackbirds" (2008). USDA National Wildlife Research Center - Staff Publications. 795.

https://digitalcommons.unl.edu/icwdm_usdanwrc/795

This Article is brought to you for free and open access by the U.S. Department of Agriculture: Animal and Plant Health Inspection Service at DigitalCommons@University of Nebraska - Lincoln. It has been accepted for inclusion in USDA National Wildlife Research Center - Staff Publications by an authorized administrator of DigitalCommons@University of Nebraska - Lincoln. 


\title{
Food color, flavor, and conditioned avoidance among red-winged blackbirds
}

\author{
Scott J. Werner ${ }^{a, *}$, Bruce A. Kimball ${ }^{a}$, Frederick D. Provenza ${ }^{b}$ \\ ${ }^{a}$ USDA/APHIS/WS/National Wildife Research Center, 4101 LaPorte Avenue, Fort Collins, CO 80521-2154, United States \\ ${ }^{\mathrm{b}}$ Department of Wildland Resources, Utah State University, Logan, UT 84322-5230, United States
}

Received 15 December 2006; received in revised form 31 July 2007; accepted 7 August 2007

\begin{abstract}
The relationship between food flavors and postingestive feedback enables mammalian herbivores to procure nutrients and avoid toxins within ever-changing environments. We conducted four experiments with red-winged blackbirds (Agelaius phoeniceus) in captivity to determine the relative roles of color and flavor cues paired with negative postingestive feedback. We first conducted baseline tests to assess preferences for colors and flavors. All blackbirds preferred red- to blue-colored food, and they preferred umami- (L-alanine) flavored to bitter/astringent food (tannic acid). We observed no difference in consumption of salty $(\mathrm{NaCl}) v s$ sour (citric acid) foods during baseline tests (i.e., neutral flavors). We then conditioned experimentally naïve blackbirds with intraperitoneal injections of lithium chloride ( $\mathrm{LiCl}$ ) to avoid food treated with red and $\mathrm{L}$ alanine, or red and $\mathrm{NaCl}$ ( $n=30$ birds per conditioning group). Subsequent to conditioning with $\mathrm{LiCl}$, three test groups were established from each conditioned group to evaluate color and flavor preferences, and preferences for novel color-flavor pairings (e.g., red/tannic acid $v s$ blue/Lalanine). Blackbirds avoided red and salty food throughout the 4-day test. Avoidance conditioned with LiCl extinguished for preferred flavors, but not for colors, of food. Conditioning affected indifference for the otherwise preferred flavor and avoidance for the otherwise neutral flavor. Relative to the neutral-flavor conditioning group, the group conditioned with a preferred flavor exhibited stronger conditioned avoidance of colored food. Unlike conditioned flavor avoidance, birds were conditioned to avoid red food only when blue food was made familiar prior to conditioning. Collectively, these results illustrate that blackbirds used affective processes (flavor-feedback relationships) to shift preference for both novel and familiar flavors, and cognitive associations (colors) to avoid food, subsequent to toxin exposure. We discuss the opportunities afforded by affective and cognitive processing for reducing agricultural damage caused by blackbirds.
\end{abstract}

(C) 2007 Elsevier Inc. All rights reserved.

Keywords: Agelaius phoeniceus; Aversive conditioning; Chemical repellent; Foraging behavior; Preference; Sensory cue; Wildlife damage management

Mammalian herbivores integrate food flavors with postingestive consequences to procure nutrients and avoid toxins $[1,2]$. This exchange of information between the internal and external milieus is processed through two interrelated systems: affective (implicit or associative) and cognitive (explicit or declarative). Taste plays a critical role in both systems. The affective system automatically (i.e., non-cognitively) integrates the taste of food with postingestive feedback from cells and organs in response to levels of ingested substances - nutrients, toxins, medicines. The net result is incentive modification due to changes in well-being. On the other hand, the cognitive system integrates the odor and sight of food with its taste. Animals use the senses of smell and sight to differentiate among foods, and to select or avoid foods whose effect is internally

\footnotetext{
* Corresponding author. Tel.: +1 970266 6136; fax: +1 9702666138 .

E-mail address: Scott.J.Werner@aphis.usda.gov (S.J. Werner).
}

positive or aversive. The net result is behavior modification. Together, affective and cognitive processes enable animals to function and maintain well-being within ever-changing environments [2].

The relevant sensory physiology [3] and the processes of food and habitat selection are less understood for wild birds. Because vision is fundamental to avian foraging behavior, the role of visual cues in flavor aversion learning has been investigated in field and pen studies. While tastes are likely the most potent conditional stimuli in the process of mammalian food consumption [4], food preference among bobwhite quail (Colinus virginianus) is affected by the color of food, and visual stimuli can actually overshadow salient tastes upon conditioning illness-induced aversions [5]. Food aversions can be reliably conditioned in red-winged blackbirds (Agelaius phoeniceus) using toxic gavage (methiocarb and $\mathrm{LiCl}$ ) paired with colored oats [6]: oats colored differently from the color paired with $\mathrm{LiCl}$ 
were preferred through 4 weeks of post-treatment testing. Furthermore, conspecifics that observed aversive conditioning events similarly formed aversions to colors paired with toxicosis, even though they did not ingest the toxin themselves [7]. Similarly, quelea (Quelea quelea) [8] and eared doves (Zenaida auriculata) [9] avoided calcium carbonate-treated crops when presence of the white powder was associated with methiocarb-induced toxicosis. Thus, at least for granivorous birds, color may be the dominant cognitive cue during the food consumption process and visual stimuli may enhance the efficacy of chemical repellents used to reduce bird damage to agricultural production $[10,11]$.

While they may have the requisite anatomy to form flavorfeedback relationships, birds have few taste buds relative to other vertebrates [3]. Unlike mammals, avian taste buds are not located in the papillae or the anterior tongue. Rather, the greatest numbers of avian taste receptors are located on the posterior tongue and pharyngeal floor [12]. While the lingual branch of the glossopharyngeal nerve was previously considered the only gustatory nerve in birds [13], the palatine branch of the facial nerve [14] and the chorda tympani [15] also transmit gustatory information. Glossopharyngeal afferents of birds enter the medulla and join fibers from the facial and vagus nerves to form the fasciculus solitarius [16]. These anatomical findings are consistent with observations in pigeons [17] and domestic chicks [18] that taste plays a critical role in the formation of aversions to foods and to the exteroceptive attributes of foods such as color.

Given these findings, we wanted to explore the relationship between visual and taste cues and postingestive feedback from $\mathrm{LiCl}$ in captive red-winged blackbirds. To do so, we first assessed their preferences for two colors (red- $v s$ blue-colored rice) and four flavors in two combinations (L-alanine- vs tannic acidflavored rice; $\mathrm{NaCl}-v s$ citric acid-flavored rice). After assessing baseline preferences, we determined if we could condition avoidance for preferred colors and flavors with negative postingestive feedback from $\mathrm{LiCl}$. We tested three hypotheses. If neuroanatomy constrains avian gustation (hypothesis 1), then we predicted blackbirds would be unable to discriminate flavors previously paired with negative postingestive consequences but they would avoid colors. Alternatively (hypothesis 2), based on the neural convergence hypothesis [1] - vagal afferents mediating gustatory and visceral sensations - and the cue-consequence [19] and skin-gut specificity [20] of conditioning contingencies, we predicted blackbirds would avoid flavors previously paired with negative postingestive consequences. Finally, foraging biases [21] and baseline preferences affect conditioned avoidance (hypothesis 3). Thus, relative to preferred colors and flavors, we predicted that blackbirds would avoid colors and flavors for which baseline indifference or aversion existed.

\section{General methods}

\subsection{Bird subjects and testing facilities}

We conducted four feeding experiments with red-winged blackbirds at the outdoor animal research facility of the National Wildlife Research Center (NWRC) in Fort Collins, CO (USA).
All birds were maintained in $4.9 \times 2.4 \times 2.4$-m cages within an open-sided building for $>2$ weeks prior to the experiments. During quarantine and holding, birds were provided free access to grit (sand) and maintenance food (2 millet:1 milo:1 safflower:1 sunflower). Feeding experiments were conducted within individual cages $(0.9 \times 1.8 \times 0.9 \mathrm{~m})$ in an open-sided building. We provided water ad libitum to all birds throughout the experiments.

\subsection{Statistical analyses}

The dependent measure for preference testing associated with Experiments 1-4 was average consumption of colored or flavored rice throughout each 4-day test. Test consumption data for each test of Experiments 1 and 2 were subjected to a repeated measures ANOVA. The random effect of our models was bird subjects, the between-subjects effect was cue (color in Experiment 1, flavor in Experiment 2), and the within-subject effect was test day. We evaluated the main effect of cue and the cue-by-day interaction using the mixed procedure of SAS. We used descriptive statistics (mean $\pm \mathrm{SE}$ ) to summarize test consumption.

Test consumption data for both conditioning groups of Experiment 3 and both tests of Experiment 4 were also subjected to a repeated measures ANOVA. The random effect of our models was bird subjects, the between-subjects effects were cues (test colors and flavors) and test groups, and the withinsubject effect was test day. We evaluated the cue-by-group and cue-by-group-by-day interactions using the mixed procedure of SAS. We used Tukey's tests to separate the means of significant $(\alpha=0.05)$ interactions and descriptive statistics (mean $\pm \mathrm{SE})$ to summarize test consumption.

\section{Experiment one}

\subsection{Method}

We evaluated baseline preference of red-winged blackbirds for colored (red $v s$ blue) rice seeds. We captured 11 adult redwinged blackbirds (M) near Fort Collins, $\mathrm{CO}$ and transported them to NWRC. We transferred birds to individual cages following group quarantine and holding, and offered each bird unadulterated seed rice (ad libitum) in each of two food bowls for 5 days (Wed-Sun).

Following acclimation, we offered one bowl of red rice and one bowl of blue rice, daily to each blackbird during a 4-day preference test (Mon-Thur). Seed treatments included $100 \mathrm{~g}$ of red \#40 or blue \#2 (FD\&C aluminum lake dispersions; Roha U. S.A., L.L.C., St. Louis, MO) and 11 of water. We uniformly applied aqueous solutions to $10 \mathrm{~kg}$ certified seed rice (Louisiana State University Rice Research Station, Crowley) using a rotating mixer and household spray equipment. We randomized the north-south positioning of colored rice within individual cages on the first day, and alternated positioning on subsequent days of the test (e.g., red rice on north, days 1 and 3).

We measured daily rice consumption throughout the preference test (Tue-Fri). We collected unconsumed rice 
(remaining in food bowls) and rice spillage (remaining in trays beneath each bowl) at 0800-0930 h, daily, and determined their mass $( \pm 0.1 \mathrm{~g})$. Cage sides were sufficiently separated $(>1.5 \mathrm{~m})$ to enable us to measure consumption independently for food bowls located on the north and south sides of each cage. We accounted for changes in the mass of rice independent of rice consumption (e.g., desiccation) by weighing rice offered within a vacant cage throughout testing.

\subsection{Results and discussion}

All red-winged blackbirds consistently preferred red rice when offered a choice between rice treated with red or blue coloring $(F(1,10)=136.95, p=0.0001)$. Average consumption of red and blue rice was $8.7 \mathrm{~g}( \pm 0.5)$ and $0.5 \mathrm{~g}( \pm 0.4)$, respectively, during the 4-day preference test. We observed no color-by-day interaction $(F(6,60)=0.83, p=0.5539)$. We attempted to condition blackbirds to avoid red rice in Experiment 3.

\section{Experiment two}

\subsection{Method}

We evaluated baseline preference of red-winged blackbirds for flavored (umami, bitter/astringent, salt, sour) rice seeds. We captured 18 adult red-winged blackbirds (M) near Fort Collins, $\mathrm{CO}$ and transported them to NWRC. We transferred birds to individual cages following group quarantine and holding, and offered each bird $100 \mathrm{~g}$ of unadulterated seed rice in each of two food bowls for 5 days (Wed-Sun). We measured rice consumption on the last day of the acclimation period.

We ranked blackbirds based upon rice consumption observed during the acclimation period and assigned them to one of two test groups ( $n=9$ birds per group). We randomly assigned flavor treatments to test groups. Red-winged blackbirds previously exhibited preference for umami-flavored and salty water, avoidance of bitter/astringent and sour water, and indifference to sweet water [22]. We offered one bowl of umami-flavored rice (L-alanine) and one bowl of bitter/ astringent rice (tannic acid), daily to each blackbird in group 1 during a 4-day preference test (Mon-Thur). We offered one bowl of salty rice $(\mathrm{NaCl})$ and one bowl of sour rice (citric acid) to each bird in group 2 .

Seed treatments included $300 \mathrm{~g}$ L-alanine, $200 \mathrm{~g}$ tannic acid, $300 \mathrm{~g} \mathrm{NaCl}$, or $150 \mathrm{~g}$ citric acid (Sigma-Aldrich, Inc., Bellefonte, PA). Tested flavor concentrations were based upon previous flavor preference trials with red-winged blackbirds [22]. We uniformly applied aqueous solutions $(100 \mathrm{ml} / \mathrm{kg})$ to $10 \mathrm{~kg}$ certified seed rice (Louisiana State University Rice Research Station, Crowley) using a rotating mixer and household spray equipment. We randomized the north-south positioning of flavored rice within individual cages on the first day, and alternated positioning on subsequent days of the test (e.g., umami-flavored rice on north, days 1 and 3 ). We measured daily rice consumption, and accounted for rice spillage and desiccation, throughout the preference test (Tue-Fri).

\subsection{Results and discussion}

Blackbirds consistently preferred L-alanine-flavored rice to tannic acid-flavored rice during the baseline preference test $(F$ $(1,8)=97.52, p=0.0001)$. Although they consumed an average of $2.4 \mathrm{~g}( \pm 1.1)$ of rice treated with tannic acid on day 1, all birds markedly decreased their intake of tannic acid after the first day of the test. On average, blackbirds consumed $6.4 \mathrm{~g}( \pm 0.5)$ of rice treated with L-alanine and $0.7 \mathrm{~g}( \pm 0.4)$ of rice treated with tannic acid. We observed no flavor-by-day interaction during the L-alanine $v s$ tannic acid test $(F(6,48)=1.95, p=0.0924)$.

Birds ate similar amounts of rice treated with $\mathrm{NaCl}$ and citric acid $(F(1,8)=1.61, p=0.2403)$. Average consumption of NaCland citric acid-treated rice was $4.8 \mathrm{~g}( \pm 0.6)$ and $3.7 \mathrm{~g}( \pm 0.6)$ during the 4-day preference test. Interestingly, we observed a flavor-by-day interaction during the $\mathrm{NaCl} v s$ citric acid test $(F$ $(6,44)=2.32, p=0.0493$; i.e. more $\mathrm{NaCl}$ consumed on days 1 and 3). Whereas the north-south positioning of flavored rice was alternated daily throughout the test, we observed a cage side preference independent of $\mathrm{NaCl}$ and citric acid seed treatments. Thus, contextual cues can affect foraging preferences (Experiment 2) and aversions [23] in passerines. We attempted to condition blackbirds to avoid rice flavored with Lalanine or $\mathrm{NaCl}$ in Experiment 3.

\section{Experiment three}

\subsection{Method}

We used avoidance conditioning to evaluate the relative roles of color and flavor cues among blackbirds feeding in captivity. We paired induced toxicosis with otherwise preferred or neutral

Table 1

Schedule for conditioning ( $n=30$ birds per conditioning group) and preference testing ( $n=10$ birds per test group) associated with conditioned avoidance among red-winged blackbirds

\begin{tabular}{lll}
\hline Experiment 3 & Conditioning group 1 & Conditioning group 2 \\
\hline $\begin{array}{l}\text { Pretreatment exposure (4 days) } \\
\text { Food bowl 1 }\end{array}$ & Blue/tannic acid & Blue/citric acid \\
Food bowl 2 & Blue/tannic acid & Blue/citric acid \\
LiCl conditioning (1 day) & Red/L-alanine & Red/NaCl \\
Food bowl 1 & Red/L-alanine & Red/NaCl \\
Food bowl 2 & & \\
Preference testing (4 days) & Test group 1A & Test group 2A \\
Color preference test & Red & Red \\
Food bowl 1 & Blue & Blue \\
Food bowl 2 & Test group 1B & Test group 2B \\
Flavor preference test & L-alanine & NaCl \\
Food bowl 1 & Tannic acid & Citric acid \\
Food bowl 2 & Test group 1C & Test group 2C \\
Novel color-flavor pairings test & Red/tannic acid & Red/citric acid \\
Food bowl 1 & Blue/L-alanine & Blue/NaCl \\
Food bowl 2 &
\end{tabular}

Conditioning group 1 was conditioned with $\mathrm{LiCl}$ to avoid an otherwise preferred color and flavor (L-alanine). Conditioning group 2 was conditioned with $\mathrm{LiCl}$ to avoid an otherwise preferred color and neutral flavor $(\mathrm{NaCl})$. Daily food consumption in each of two food bowls was measured to evaluate color preference (test groups 1A and 2A), flavor preference (1B and 2B), and preference for novel color-flavor pairings ( $1 \mathrm{C}$ and $2 \mathrm{C}$ ) subsequent to $\mathrm{LiCl}$ conditioning. 
a

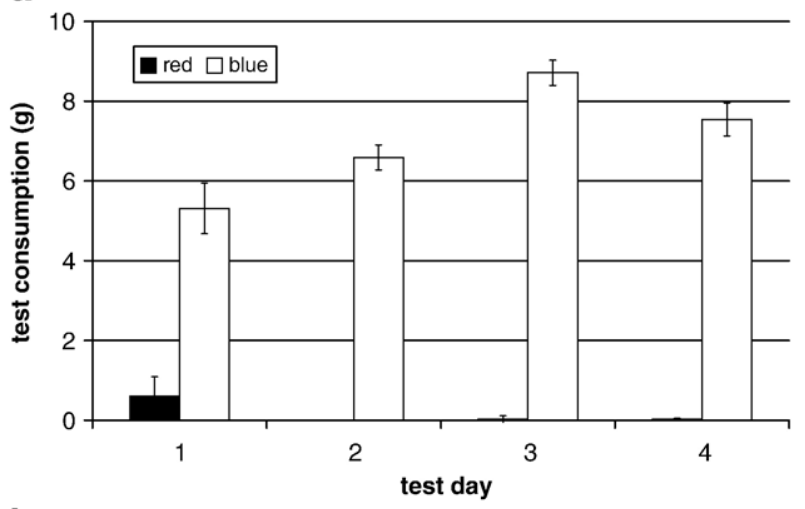

b

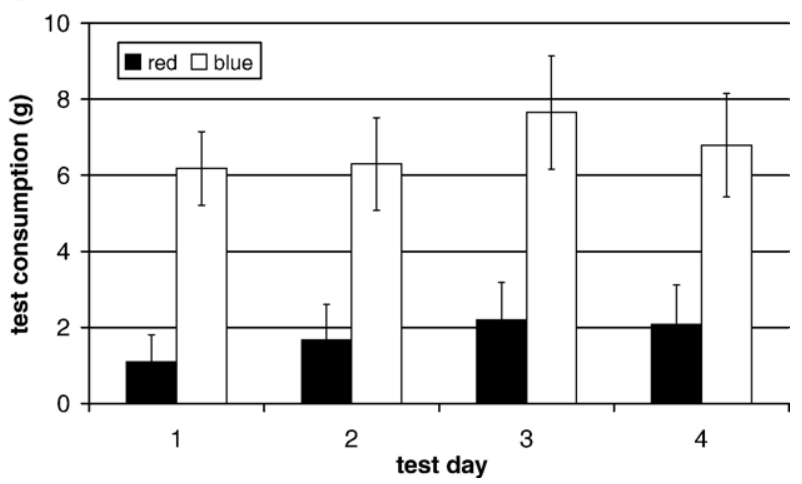

Fig. 1. Color preferences among red-winged blackbirds $(n=10)$ subsequent to conditioning with $\mathrm{LiCl}$ paired with (a) red and L-alanine treated rice, or (b) red and $\mathrm{NaCl}$-treated rice. Data represent average $( \pm \mathrm{SE})$ daily consumption during 4 test days subsequent to $\mathrm{LiCl}$ exposure. An independent group of red-winged blackbirds consumed an average of $8.7 \mathrm{~g}$ of red rice (preferred color) $v s 0.5 \mathrm{~g}$ of blue rice during Experiment 1.

cues, and evaluated resultant color and flavor preferences to test our hypotheses of avian foraging behavior. We captured 60 adult red-winged blackbirds (M) near Fort Collins, $\mathrm{CO}$ and transported them to NWRC. We transferred birds to individual cages following group quarantine and holding, and offered each bird unadulterated seed rice (ad libitum) in each of two food bowls for 5 days (Wed-Sun).

Following acclimation, we randomly assigned blackbirds to one of two conditioning groups ( $n=30$ birds per group) and offered each bird two food bowls at 0800-0930 h, daily for four pretreatment days (Mon-Thur). For birds in conditioning group 1 , both food bowls contained $30 \mathrm{~g}$ of seed rice treated with the blue lake dispersion and tannic acid (Table 1). For birds in conditioning group 2, both food bowls contained $30 \mathrm{~g}$ of seed rice treated with the blue lake dispersion and citric acid. Seed treatments included formulations of Experiments 1 and 2.

We removed the pretreatment diet at $1600-1700 \mathrm{~h}$ on Thursday of the pretreatment (i.e., the day prior to $\mathrm{LiCl}$ conditioning). We offered two food bowls at $0430 \mathrm{~h}$ on the subsequent day (Friday). For birds in conditioning group 1, both food bowls contained $30 \mathrm{~g}$ of seed rice treated with the red lake dispersion and L-alanine (Table 1). For birds in conditioning group 2, both food bowls contained $30 \mathrm{~g}$ of seed rice treated with the red lake dispersion and $\mathrm{NaCl}$. For the purpose of avoidance conditioning, each bird received a $10-\mathrm{ml} / \mathrm{kg}$ intraperitoneal injection of $0.3 \mathrm{M} \mathrm{LiCl}$ [17] between 0900 and $1000 \mathrm{~h}$ on Friday. We measured rice consumption at 1100 $1200 \mathrm{~h}$. For each conditioning group, we ranked blackbirds based upon rice consumption observed during $\mathrm{LiCl}$ conditioning and assigned them to one of three test groups ( $n=10$ birds per each of 6 test groups). We randomly assigned test cues among groups. We provided maintenance food (2 millet:1 milo:1 safflower:1 sunflower; ad libitum) in each of two food bowls to all birds for three days (Fri-Sun) following $\mathrm{LiCl}$ conditioning, beginning 1100-1200 h on Friday.

We offered two food bowls (30 g rice each) at 0800-0930 h, daily for 4 days of preference testing (Mon-Thur). For conditioning groups 1 and 2, we evaluated color preference with test groups $1 \mathrm{~A}$ and $2 \mathrm{~A}$, respectively (Table 1). We evaluated flavor preference with test groups $1 \mathrm{~B}$ and $2 \mathrm{~B}$. We evaluated preference for novel color-flavor pairings (red/tannic acid $v s$ blue/L-alanine and red/citric acid $v s$ blue $/ \mathrm{NaCl}$ ) with test groups $1 \mathrm{C}$ and $2 \mathrm{C}$. The north-south placement of food bowls was randomized on the first day and alternated on subsequent days of the preference test. We measured daily rice consumption, and accounted for rice spillage and desiccation throughout preference testing (Tue-Fri).
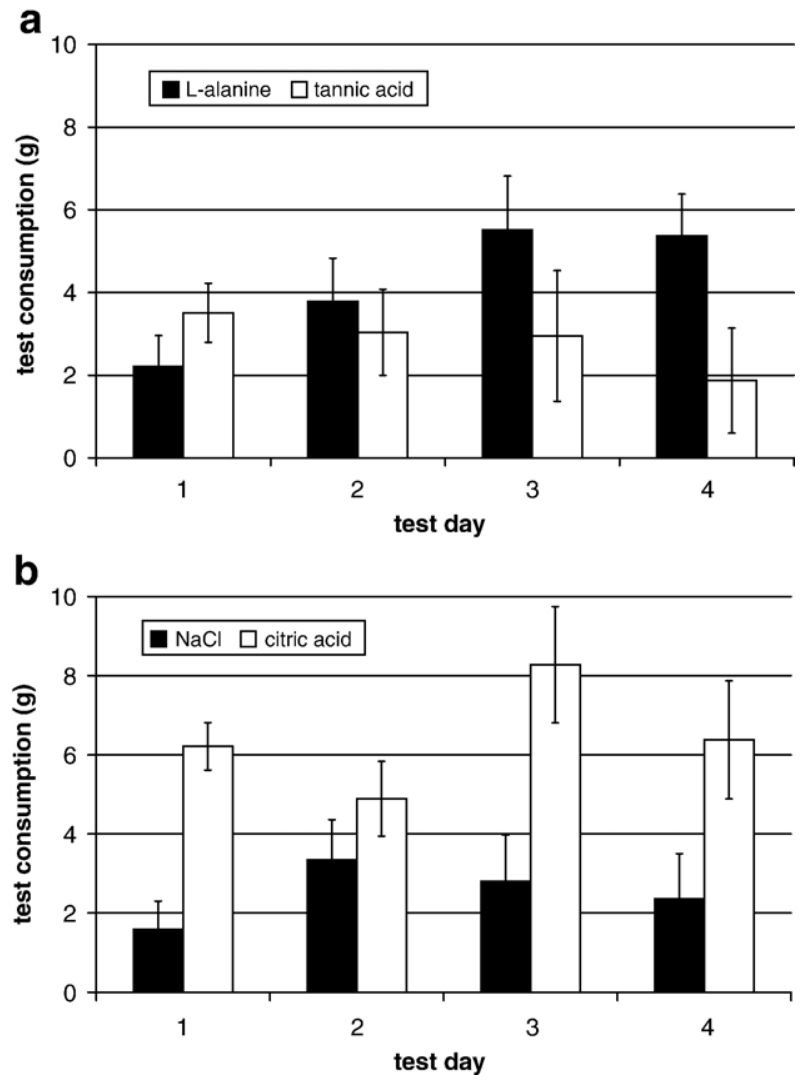

Fig. 2. Flavor preferences among red-winged blackbirds $(n=10)$ subsequent to conditioning with $\mathrm{LiCl}$ paired with (a) red and L-alanine treated rice, or (b) red and $\mathrm{NaCl}$-treated rice. Data represent average $( \pm \mathrm{SE})$ daily consumption during 4 test days subsequent to $\mathrm{LiCl}$ exposure. Independent groups of red-winged blackbirds consumed an average of $6.4 \mathrm{~g}$ of L-alanine-flavored rice (preferred flavor) $v s 0.7 \mathrm{~g}$ of tannic acid-flavored rice, and $4.8 \mathrm{~g}$ of NaCl- $v s 3.7 \mathrm{~g}$ of citric acid-flavored rice (neutral flavors) during Experiment 2. 


\subsection{Results and discussion}

With regard to the color preference test, blackbirds preferred blue to red rice subsequent to conditioning with red, L-alanine, and $\mathrm{LiCl}$ (Tukey $p=0.0001$ ). Average consumption of red and blue rice was $0.1 \mathrm{~g}( \pm 0.1)$ and $7.0 \mathrm{~g}( \pm 0.3)$, respectively, for the red-L-alanine-LiCl conditioning group during the 4-day preference test (Fig. 1a). Similarly, blackbirds conditioned to avoid rice treated with red and $\mathrm{NaCl}$ preferred blue rice throughout the test (Tukey $p=0.0001$ ). Average consumption of red and blue rice was $1.8 \mathrm{~g}( \pm 0.4)$ and $6.7 \mathrm{~g}( \pm 0.6)$, respectively, for the red- $\mathrm{NaCl}-\mathrm{LiCl}$ conditioning group (Fig. 1b). Thus, we observed a cue-by-group interaction for the red, L-alanine, $\mathrm{LiCl}$ $(F(5,45)=21.27, p=0.0001)$, and the red, $\mathrm{NaCl}, \mathrm{LiCl}$ conditioning groups $(F(5,43)=8.83, p=0.0001)$. We observed no cue-group-day interaction for the red, L-alanine, $\mathrm{LiCl}(F(18$, $162)=0.91, p=0.5614)$, and the red, $\mathrm{NaCl}, \mathrm{LiCl}$ conditioning groups $(F(18,155)=0.49, p=0.9596)$.

With regard to the flavor preference test, we observed no difference in consumption of rice treated with L-alanine $(4.2 \pm$ $0.5 \mathrm{~g}) v s$ tannic acid $(2.8 \pm 0.6 \mathrm{~g})$ during the test (Tukey $p=0.4137$; Fig. 2a). However, their pattern of consumption of L-alanine and tannic acid changed markedly from baseline in
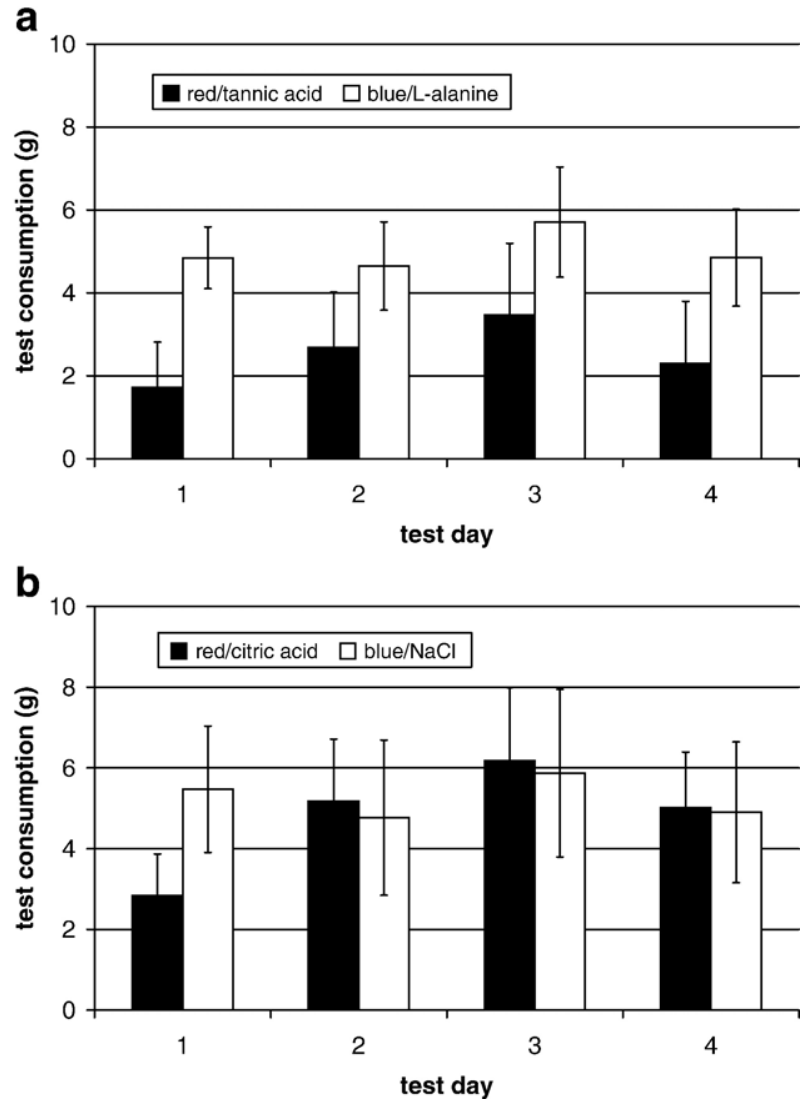

Fig. 3. Relative roles of color and flavor cues for conditioned avoidance among red-winged blackbirds in captivity. Conditioning groups ( $n=30$ birds per group) were used to pair $\mathrm{LiCl}$ with (a) red and L-alanine treated rice, or (b) red and $\mathrm{NaCl}$-treated rice. Test groups ( $n=10$ birds per group) were used to evaluate conditioned avoidance of novel color-flavor pairings. Data represent average $( \pm \mathrm{SE}$ ) daily consumption during 4 test days subsequent to $\mathrm{LiCl}$ exposure.
Table 2

Schedule for conditioning and preference testing ( $n=11$ birds per group) associated with conditioned avoidance among red-winged blackbirds

\begin{tabular}{|c|c|c|c|c|}
\hline \multirow[t]{2}{*}{ Experiment 4} & \multicolumn{2}{|l|}{ Test 1} & \multicolumn{2}{|l|}{ Test 2} \\
\hline & Group 1 & Group 2 & Group 1 & Group 2 \\
\hline \multicolumn{5}{|c|}{ Pretreatment (4 days) } \\
\hline Food bowl 1 & Blue & Citric acid & Untreated rice & Untreated rice \\
\hline Food bowl 2 & Blue & Citric acid & Untreated rice & Untreated rice \\
\hline \multicolumn{5}{|c|}{$\mathrm{LiCl}$ conditioning ( 1 day) } \\
\hline Food bowl 1 & Red & $\mathrm{NaCl}$ & Red & $\mathrm{NaCl}$ \\
\hline Food bowl 2 & Red & $\mathrm{NaCl}$ & Red & $\mathrm{NaCl}$ \\
\hline \multicolumn{5}{|c|}{ Preference testing (4 days) } \\
\hline Food bowl 1 & Red & $\mathrm{NaCl}$ & Red & $\mathrm{NaCl}$ \\
\hline Food bowl 2 & Blue & Citric acid & Blue & Citric acid \\
\hline
\end{tabular}

Tests 1 and 2 were designed to evaluate avoidance of red or $\mathrm{NaCl}$ with and without pretreatment exposure to comparison cues (blue or citric acid). Daily food consumption in each of two food bowls was measured to evaluate color and flavor preference subsequent to $\mathrm{LiCl}$ conditioning.

Experiment 2 (strong preference for L-alanine over tannic acid) to testing in Experiment 3 (much lower preference for L-alanine relative to tannic acid throughout testing). Blackbirds preferred rice treated with citric acid subsequent to conditioned avoidance of salty rice (Tukey $p=0.0054$ ). Average consumption of $\mathrm{NaCl}$ and citric acid-flavored rice was $2.5 \mathrm{~g}( \pm 0.5)$ and $6.4 \mathrm{~g}( \pm 0.6)$, respectively, during the 4-day preference test (Fig. 2b). Thus, blackbird preference for L-alanine-flavored rice was lost, and avoidance of $\mathrm{NaCl}$ was conditioned by $\mathrm{LiCl}$.

We also evaluated preference for novel color-flavor pairings (red/tannic acid $v s$ blue/L-alanine and red/citric acid $v s$ blue/ $\mathrm{NaCl})$. On average, blackbirds consumed $2.5 \mathrm{~g}( \pm 0.7)$ of rice treated with $\mathrm{red} / \mathrm{tannic}$ acid, and $5.0 \mathrm{~g}( \pm 0.5)$ of rice treated with blue/L-alanine (Tukey $p=0.0173$; Fig. 3a). Although blackbirds consumed more rice treated with blue/ $\mathrm{NaCl} v s \mathrm{red} /$ citric acid (Fig. 3b) on test day 1, we observed no difference in rice consumption among blackbirds offered these novel colorflavor pairings on days 2-4. Average consumption of rice treated with $\mathrm{red} /$ citric acid and blue/ $\mathrm{NaCl}$ was $4.8 \mathrm{~g}( \pm 0.7)$ and $5.3 \mathrm{~g}( \pm 0.9)$, respectively (Tukey $p=0.9967)$.

\section{Experiment four}

\subsection{Method}

We conducted two additional tests to investigate the influence of pretreatment exposure to comparison cues (blue, citric acid) and single-element conditioning ( $\mathrm{LiCl}$ with red or $\mathrm{NaCl}$ ). We paired induced toxicosis with an otherwise preferred color or neutral flavor, and evaluated resultant color and flavor preferences as comparative controls for Experiment 3. Thus, tests 1 and 2 included single-element conditioning with and without pretreatment exposure to comparison cues, respectively.

We captured 39 adult red-winged blackbirds (M) near Fort Collins, CO and transported them to NWRC. We transferred birds to individual cages following group quarantine and holding, and offered each bird $80 \mathrm{~g}$ of unadulterated seed rice in each of two food bowls for 5 days (Wed-Sun). We ranked 
blackbirds based upon rice consumption observed during the acclimation period. We assigned birds to one of two groups for each of the two tests $(n=8-10$ birds per group; Table 2$)$ and randomly assigned seed treatments between groups.

Following acclimation, we offered each bird two food bowls at 0800-0930 h, daily for four pretreatment days (Mon-Thur). For birds in test 1 , both food bowls contained $30 \mathrm{~g}$ of seed rice treated with blue lake dispersion (group 1) or citric acid (group 2 ). For birds in test 2, both food bowls contained $30 \mathrm{~g}$ of untreated rice (Table 2). Seed treatments included formulations of Experiments 1-3.

We removed the pretreatment diet at $1600-1700 \mathrm{~h}$ on Thursday of the pretreatment (i.e., the day prior to $\mathrm{LiCl}$ conditioning). We offered two food bowls at $0430 \mathrm{~h}$ on the subsequent day (Friday). For tests 1 and 2, all birds in groups 1 and 2 were offered two food bowls that contained $30 \mathrm{~g}$ of seed rice treated with either red lake dispersion (group 1) or sodium chloride (group 2) (Table 2). For the purpose of avoidance conditioning, each bird received a $10-\mathrm{ml} / \mathrm{kg}$ intraperitoneal injection of $0.3 \mathrm{M} \mathrm{LiCl}$ [17] between 0900 and $1000 \mathrm{~h}$ on Friday. We provided maintenance food (2 millet:1 milo:1 safflower: 1 sunflower; ad libitum) in each of two food bowls to all birds for three days (Fri-Sun) following $\mathrm{LiCl}$ conditioning, beginning $1100-1200 \mathrm{~h}$ on Friday.

a

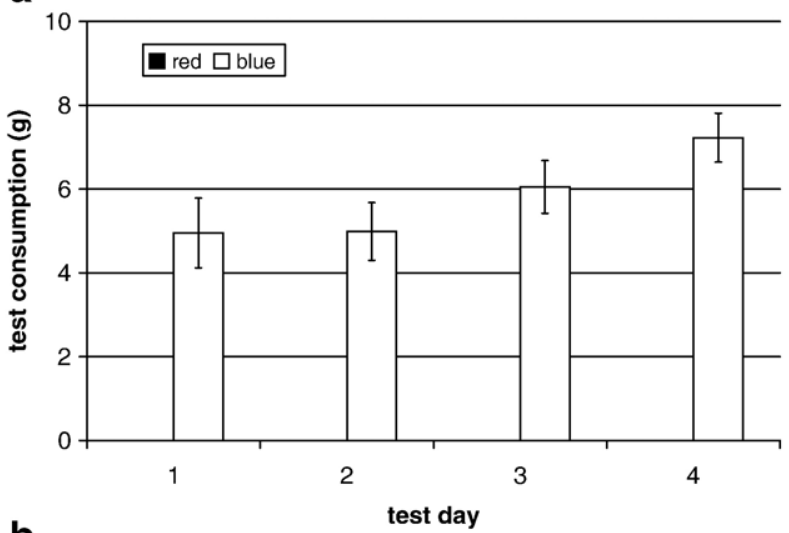

b

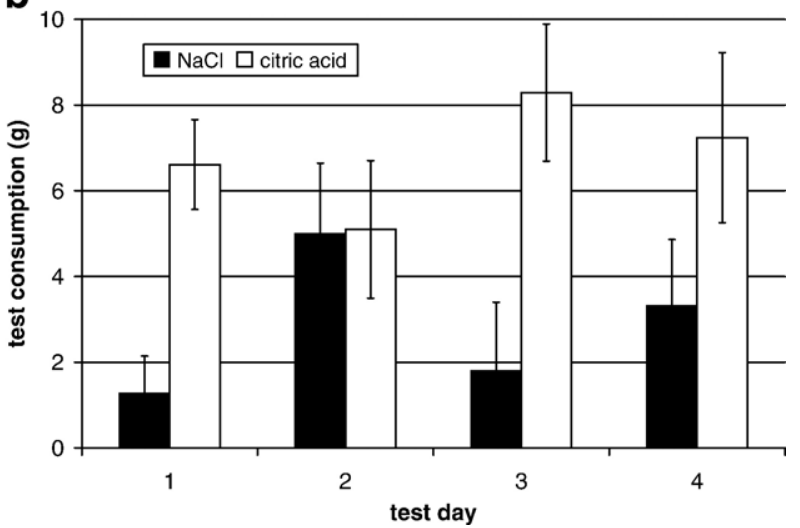

Fig. 4. Color and flavor preferences among red-winged blackbirds subsequent to conditioning with $\mathrm{LiCl}$ paired with (a) red-colored rice $(n=8)$ or (b) $\mathrm{NaCl}$ flavored rice $(n=10)$ and pretreatment exposure to comparison cues (familiar blue or citric acid). Data represent average $( \pm \mathrm{SE}$ ) daily consumption during 4 test days subsequent to $\mathrm{LiCl}$ exposure.
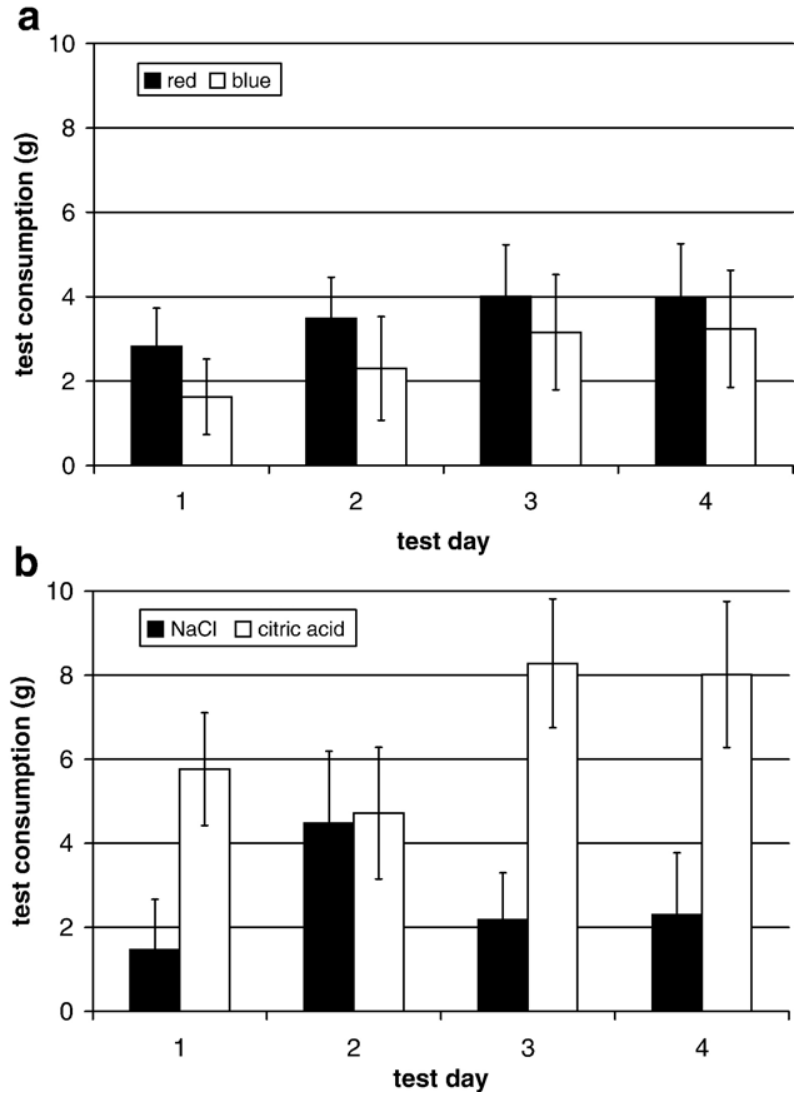

Fig. 5. Color and flavor preferences among red-winged blackbirds subsequent to conditioning with $\mathrm{LiCl}$ paired with (a) red-colored rice $(n=10)$ or (b) $\mathrm{NaCl}$ flavored rice $(n=11)$ and no pretreatment exposure to comparison cues (novel blue or citric acid). Data represent average ( \pm SE) daily consumption during 4 test days subsequent to $\mathrm{LiCl}$ exposure.

We offered two food bowls (30 g rice each) at 0800-0930 h, daily for 4 days of preference testing (Mon-Thur). For both tests, we evaluated color (red $v s$ blue) and flavor $(\mathrm{NaCl} v s$ citric acid) preference of groups 1 and 2, respectively (Table 2). The north-south placement of food bowls was randomized on the first day and alternated on subsequent days of the preference test. We measured daily rice consumption, and accounted for rice spillage and desiccation throughout preference testing (Tue-Fri).

\subsection{Results and discussion}

In test 1 , blackbirds with pretreatment exposure to blue or citric acid preferred blue to red rice (Tukey $p=0.0001$; Fig. $4 \mathrm{a}$ ) and citric acid- to NaCl-flavored rice (Tukey $p=0.0006$; Fig. 4b) after conditioning with red and $\mathrm{LiCl}$ or $\mathrm{NaCl}$ and $\mathrm{LiCl}$, respectively. Average consumption of red and blue rice was $0 \mathrm{~g}$ $( \pm 0.1)$ and $5.7 \mathrm{~g}( \pm 0.4)$, respectively. On average, blackbirds consumed $2.8 \mathrm{~g}( \pm 0.7)$ of rice treated with $\mathrm{NaCl}$ and $6.8 \mathrm{~g}( \pm 0.8)$ of rice treated with citric acid. Thus, we observed a cue-by-group interaction $(F(3,23)=25.22, p=0.0001)$ and no cue-group-day interaction $(F(12,96)=0.94, p=0.5084)$ during test 1 .

In test 2 , we observed no difference in consumption of red and blue rice among blackbirds with no pretreatment exposure 
to blue rice (Tukey $p=0.7500$; Fig. 5a). Average consumption of red and blue rice was $3.6 \mathrm{~g}( \pm 0.5)$ and $2.6 \mathrm{~g}( \pm 0.6)$, respectively. Pretreatment exposure to blue rice (familiar comparison color) was thus necessary to condition avoidance of red rice in Experiments 3 and 4. Conversely, blackbirds with no pretreatment exposure to citric acid-flavored rice (novel comparison flavor) avoided $\mathrm{NaCl}$-flavored rice subsequent to $\mathrm{LiCl}$ conditioning (Tukey $p=0.0010$; Fig. 5b). On average, blackbirds consumed $2.6 \mathrm{~g}( \pm 0.7)$ of rice treated with $\mathrm{NaCl}$ and $6.7 \mathrm{~g}( \pm 0.8)$ of rice treated with citric acid. Thus, we observed a cue-by-group interaction $(F(3,28)=8.45, p=0.0004)$ and no cue-group-day interaction $(F(12,114)=0.77, p=0.6846)$ during test 2. Pretreatment exposure to the comparison flavor was not necessary to condition flavor avoidance in Experiments 3 and 4.

\section{General discussion}

These experiments illustrate the relative roles of food color and flavor for red-winged blackbirds. Blackbirds reliably discriminated flavored food prior and subsequent to $\mathrm{LiCl}$ exposure, apparent neuroanatomical constraints notwithstanding (hypothesis 1). Consistent with the neural convergence hypothesis (hypothesis 2), blackbirds avoided flavors previously paired with toxicosis. Although avoidance of red- and $\mathrm{NaCl}-$ treated food persisted, baseline flavor preference resumed by test day 2 for groups tested with novel color-flavor pairings and a preferred flavor (L-alanine). Thus, nontoxic consequences affected flavor preference during the 4-day test subsequent to toxin exposure.

Consistent with our third hypothesis, foraging biases and baseline preferences affected conditioned avoidance of flavors. While $\mathrm{LiCl}$ decreased preference for $\mathrm{L}$-alanine relative to tannic acid, blackbirds gradually reverted to a preference for L-alanine over tannic acid (Fig. 2a), likely due to the aversive postingestive consequences of ingesting tannic acid [1,2]. Conversely, $\mathrm{LiCl}$ conditioned a more lasting avoidance of $\mathrm{NaCl}$ relative to citric acid (Fig. 2b). Thus, conditioning affected indifference for L-alanine (the otherwise preferred flavor) and avoidance of $\mathrm{NaCl}$ (the otherwise neutral flavor). Moreover, the group conditioned with the preferred flavor exhibited stronger conditioned avoidance of colored (red) food $(95 \% \mathrm{CI}=-0.1-$ 0.4 g; Fig. 1a) than the neutral-flavor conditioning group $(95 \%$ $\mathrm{CI}=0.9-2.6$ g; Fig. 1b).

Blackbirds responded differently to the effects of $\mathrm{LiCl}$ in tests 1 and 2 of Experiment 4 (Table 2, Figs. 4 and 5). Blackbirds were conditioned to avoid red food only when blue food was made familiar prior to conditioning in Experiment 4 (Figs. 4a vs 5a). Conversely, blackbirds avoided $\mathrm{NaCl}$-flavored food when citric acid was familiar (Fig. 4b) or novel (Fig. 5b) during the test. These results suggest that the familiar-novel dichotomy so important for conditioning flavor aversions in mammals $[2,24]$ is necessary for conditioning avoidance of color cues in blackbirds.

For mammalian herbivores, affective processes involve integrating taste with postingestive feedback; cognitive processes involve integrating the senses of smell, sight, and hearing with taste-postingestive feedback $[1,2]$. Blackbirds used affective processes to shift flavor preference, and cognitive associations to avoid food, following toxin exposure. We observed no extinction of avoidance conditioned for red food during the 6 days subsequent to $\mathrm{LiCl}$ exposure. Color cues alone, however, are unlikely to condition avoidance among avian foragers $[25,26]$.

Chemical repellents can act by eliciting withdrawal from specific or combined sensory stimuli (e.g., odor, taste) [27], or by producing learned avoidance via association between adverse postingestive effects and specific sensory cues (e.g., taste, odor) [27]. In contrast to a mere reduction in food consumption, avoidance is characterized by the discontinued sampling or consumption of foods, and/or the discontinued occupancy of places, previously associated with an aversive stimulus [28].

An organism exhibits avoidance by evading an aversive event (e.g., adverse postingestive effects) and its associated cues. For blackbirds, these cues include food color and flavor. Avoidance is a prudent behavioral application and management goal when 1) economic or environmental constraints limit the rate and frequency of repellent applications, and/or 2) degradation of the active ingredient is expected within the period of needed repellency. Affective processes will shift flavor preferences in the absence of sufficient aversive consequences associated with limited or degraded repellent applications.

Our understanding of avian foraging behavior can be applied in myriad contexts of agricultural damage management. Although no effective avian repellents are presently registered for agricultural applications in the United States, nontoxic and nonlethal repellents designed to create strong food aversions, perhaps by acting specifically on the emetic system of the midbrain and brainstem [1], are needed to reduce bird damages to newly planted and ripening crops [29]. Indeed, the elucidation of color and flavor preferences, and relevant avoidance characteristics may be useful for reducing potential hazards of pesticide delivery systems for birds [30,31] and developing chemical compounds as avian repellents [28,32]. Based upon our experiments, we recommend further evaluation of color-flavor-feedback relationships as part of avian repellent applications for reducing agricultural damage caused by blackbirds.

\section{Acknowledgments}

We thank Drs. C. Rowe, R.S. Stahl, and M.E. Tobin for their thoughtful comments on an earlier version of this manuscript. We also thank Dr. J.C. Hurley for his applied understanding of aluminum lake dispersions for our study. The capture, care, and use of animals associated with feeding experiments were approved by NWRC's Institutional Animal Care and Use Committee (NWRC Study Protocol QA1061).

\section{References}

[1] Provenza FD. Postingestive feedback as an elementary determinant of food preference and intake in ruminants. J Range Manage 1995;48:2-17. 
[2] Provenza FD, Villalba JJ. Foraging in domestic vertebrates: linking the internal and external milieu. In: Bels VL, editor. Feeding in domestic vertebrates: from structure to function. Oxfordshire: CABI Publishing; 2006. p. 210-40.

[3] Mason JR, Clark L. The chemical senses in birds. In: Whittow GC, editor. Sturkie's avian physiology. 5th ed. New York: Academic Press; 2000 p. 39-56.

[4] Garcia J. Food for Tolman: cognition and cathexis in concert. In: Archer T, Nilsson L, editors. Aversion, avoidance and anxiety. Hillsdale: Erlbaum; 1989. p. 45-85.

[5] Wilcoxon HC, Dragoin WB, Kral PA. Illness-induced aversions in rat and quail: relative salience of visual and gustatory cues. Science 1971;171:826-8.

[6] Mason JR, Reidinger RF. Importance of color for methiocarb-induced food aversions in red-winged blackbirds. J Wildl Manage 1983;47:383-93.

[7] Mason JR, Arzt AH, Reidinger RF. Comparative assessment of food references and aversions acquired by blackbirds via observational learning. Auk 1984;101:796-803.

[8] Elmahdi EM, Bullard RW, Jackson WB. Calcium carbonate enhancement of methiocarb repellency for quelea. Trop Pest Manage 1985;31:67-72.

[9] Rodriguez EN, Bruggers RL, Bullard RW, Cook R. An integrated strategy to decrease eared dove damage in sunflower crops. In: Mason JR, editor. Repellents in wildlife management: proceedings of a symposium. Fort Collins: National Wildlife Research Center; 1997. p. 409-21.

[10] Avery ML, Mason JR. Feeding responses of red-winged blackbirds to multisensory repellents. Crop Prot 1997;16:159-64.

[11] Nelms CO, Avery ML. Reducing bird repellent application rates by the addition of sensory stimuli. Int J Pest Manage 1997;43:187-90.

[12] Kare MR. Comparative study of taste. In: Beidler LM, editor. Handbook of sensory physiology. Berlin: Springer-Verlag; 1971. p. 278-92.

[13] Duncan CJ. The sense of taste in birds. Ann Appl Biol 1960;48:409-14.

[14] Krol CPM, Dubbeldam JL. On the innervation of taste buds by n. facialis in the mallard, Anas platyrhynchos L. Neth J Zool 1979;29:267-74.

[15] Gentle MJ. Single unit responses from the solitary complex following oral stimulation in the chicken. J Comp Physiol 1979;130:259-64.

[16] Wenzel BM. Chemoreception. In: Farner DS, King JR, Parkes KC, editors Avian biology, vol. 3. New York: Academic Press; 1973. p. 389-415.

[17] Westbrook RF, Clarke JC, Provost S. Long-delay learning in the pigeon: flavor, color, and flavor-mediated color aversions. Behav Neural Biol 1980;28:398-407.
[18] Franchina JJ, Moon C, Peters S. Effects of toxin magnitude on taste aversion and taste-potentiated aversion to visual cues in chicks (Gallus domesticus). Physiol Behav 1997;62:605-9.

[19] Domjan M. Cue-consequence specificity and long-delay learning revisited. Ann NY Acad Sci 1985;443:54-66.

[20] Lett BT. The pain-like effect of gallamine and naloxone differs from sickness induced by lithium chloride. Behav Neurosci 1985;99:145-50.

[21] Rowe C, Skelhorn J. Colour biases are a question of taste. Ann Behav 2005;69:587-94.

[22] Espaillat JE, Mason JR. Differences in taste preference between redwinged blackbirds and European starlings. Wilson Bull 1990;102:292-9.

[23] Tobin ME. Cues used by European starlings for detecting methiocarbtreated grapes. J Wildl Manage 1985;49:1102-8.

[24] Provenza FD, Villalba JJ, Cheney CD, Werner SJ. Self-organization of foraging behaviour: from simplicity to complexity without goals. Nutr Res Rev 1998;11:199-222.

[25] Avery ML, Humphrey JS, Decker DG, McGrane AP. Seed color avoidance by captive red-winged blackbirds and boat-tailed grackles. J Wildl Manage 1999;63:1003-8.

[26] Lyytinen A, Alatalo RV, Lindström L, Mappes J. Can ultraviolet cues function as aposematic signals? Behav Ecol 2001;12:65-70.

[27] Rogers Jr JG. Responses of caged red-winged blackbirds to two types of repellents. J Wildl Manage 1974;38:418-23.

[28] Werner SJ, Clark L. Understanding blackbird sensory systems and how repellent applications work. In: Linz GM, editor. Management of North American blackbirds. Washington, D.C.: United States Department of Agriculture; 2003. p. 31-40.

[29] Werner SJ, Homan HJ, Avery ML, Linz GM, Tillman EA, Slowik AA, et al. Evaluation of Bird Shield ${ }^{\mathrm{TM}}$ as a blackbird repellent in ripening rice and sunflower fields. Wildl Soc Bull 2005;33:251-7.

[30] Gionfriddo JP, Best LB. Grit color selection by house sparrows and northern bobwhites. J Wildl Manage 1996;60:836-42.

[31] Robel RJ, Keating JF, Zimmerman JL, Behnke KC, Kemp KE. Consumption of colored and flavored food morsels by Harris' and American tree sparrows. Wilson Bull 1997;109:218-25.

[32] Werner SJ, Cummings JL, Tupper SK, Hurley JC, Stahl RS, Primus TM. Caffeine formulation for avian repellency. J Wildl Manage 2007;71:1676-81. 